Spennrath-Kirstein

Bau und Wirkungsweise der elektrischen Maschinen.

\author{
II. Teil.
}




\section{Grundlagen der Elektrotechnik}

von

\section{O. Kirstein}

Beratender Ingenieur.

Dritte neubearbeitete Auflage von:

Die Bedienung und Wartung elektrischer Anlagen und Maschinen

von

\section{Jos. Spennrath}

weil. Direktor der städt. gew. Schulen usw. in Aachen.

I. Teil: Einführung in die Grundlagen der Elektrotechnik.

II. Teil: Einführung in den Bau und die Wirkungsweise der elektrischen Maschinen.

Berlin W

Verlag von M. Krayn.

1923. 


\section{Einführung in den Bau und die Wirkungsweise der elektrischen Maschinen}

von

Joseph Spennrath.

Dritte neubearbeitete Auflage

von

O. Kirstein.

Beratender Ingenieur.

Mit 132 Abbildungen im Text.

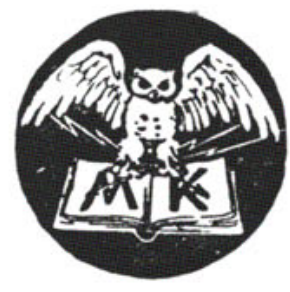

Berlin W

Verlag von M. Krayn.

1923. 
Alle Rechte vorbehalten, namentlich das der Übersetzung. 